\title{
Role and underlying mechanism of SPATA12 in oxidative damage
}

\author{
DAOBING WU, DAN LI, ZHIYONG LIU, XIAOWEN LIU, SHIHUA ZHOU and HONGYAN DUAN \\ Department of Life Science, College of Biology, Hunan University, Changsha, Hunan 410082, P.R. China
}

Received October 26, 2016; Accepted November 2, 2017

DOI: $10.3892 / 01.2018 .7749$

\begin{abstract}
Spermatogenesis-associated gene 12 (SPATA12) functions as an inhibitor in spermatogenesis and tumorigenesis. Our previous study demonstrated that SPATA12 may be induced in tumor cells by ultraviolet (UV) C-mediated DNA damage, suggesting its importance in maintaining genomic integrity. In order to understand whether and how SPATA12 responds to oxidative damage, the present study established a cellular model of oxidative stress by detecting the effect of $\mathrm{H}_{2} \mathrm{O}_{2}$ on cell viability and intracellular superoxide dismutase activity, and the levels of glutathione and malondialdehyde (MDA). Quantitative polymerase chain reaction results demonstrated that $\mathrm{H}_{2} \mathrm{O}_{2}$ upregulated the expression of SPATA12, and a dual luciferase reporter gene assay indicated that transcription factor activator protein-1 (AP-1) was involved in the response of SPATA12 to oxidative stress. Through the exogenous expression of SPATA12, it was identified that SPATA12 decreased the level of reactive oxygen species and MDA, and also may reduce the degree of cellular oxidative damage and apoptosis induced by $\mathrm{H}_{2} \mathrm{O}_{2}$. In addition, resveratrol was demonstrated to increase the expression of SPATA12 by activating AP-1, and it may be used as a nontoxic activator of the SPATA 12 gene. In conclusion, these results suggest that $S P A T A 12$ is upregulated by oxidative stress via AP-1, and that the exogenous expression of SPATA12 protects against $\mathrm{H}_{2} \mathrm{O}_{2}$-induced oxidative damage and apoptosis.
\end{abstract}

\section{Introduction}

Reactive oxygen species (ROS) are a class of free radical including hydrogen peroxide $\left(\mathrm{H}_{2} \mathrm{O}_{2}\right)$, superoxide anions $\left(\mathrm{O}_{2}^{\bullet-}\right)$ and hydroxyl radicals $(\bullet \mathrm{OH})(1)$. Compared with molecular oxygen, ROS exhibit a high reaction activity and may induce the oxidative damage of important biological molecules, including DNA, proteins and lipids. As byproducts of cellular metabolism, ROS are tightly controlled by endogenous scavenging

Correspondence to: Professor Dan Li, Department of Life Science, College of Biology, Hunan University, Zeng Xianzi Building, 1 Denggao Road, Changsha, Hunan 410082, P.R. China

E-mail: lidanie@hotmail.com

Key words: spermatogenesis-associated gene 12, oxidative damage, activator protein-1, resveratrol systems that involve catalase, superoxide dismutase (SOD) and glutathione (GSH) in living cells. Therefore, under normal circumstances, ROS exist in a physiological balance with biochemical antioxidants. However, when the levels of ROS exceed the capacity of the scavenging system, a disturbance of redox homeostasis occurs, resulting in oxidative damage and potentially, the induction of apoptosis $(2,3)$.

Oxidative damage caused by ROS has been demonstrated to be associated with a number of diseases, including malignant tumors (4). Elevated ROS levels in cells cause genomic instability, and thereby promote the activation of oncogenes and inactivation of tumor suppressor genes (5). ROS may also affect the invasion and metastasis of cancer cells through the regulation of a number of important signal transduction pathways and molecules, including mitogen-activate protein kinases, phosphoinositide 3-kinase, phosphatase and tensin homolog, redox factor-1, nuclear factor (erythroid-derived 2)-like 2, SHC-transforming protein 1, ataxia telangiectasia mutated and protein tyrosine phosphatases, suggesting that ROS serve an important role in various stages of tumorigenesis (6-8).

The spermatogenesis-associated gene 12 (SPATA12), located on chromosome $3 \mathrm{p} 14$, was identified in our previous study by digital differential display assay (9). It was then demonstrated as a stage- and cell-type-specific gene that may be involved in the development of testicular maturation, and may negatively regulate $\beta$-catenin signaling during spermatogenesis (10). Another previous study identified that SPATA12 may be an inhibitor of testicular tumorigenesis (11). Through a yeast two-hybrid screening system, fluorescence microscopy and subcellular co-localization assays, an interaction between SPATA12 and chromodomain helicase DNA binding protein 2 (CHD2) in the nucleus was demonstrated. CHD2 is a chromatin-remodeling factor required for the maintenance of genomic stability, and is involved in the later stage of the DNA damage response pathway by affecting the transcriptional activity of p53 (12). Therefore, we hypothesized and verified that SPATA12 expression may be induced under ultraviolet (UV) C stress, and demonstrated that SPATA12 expression was associated with the inhibition of cellular proliferation subsequent to UVC-irradiated DNA damage (13). These data suggest that SPATA12 may serve an important role in maintaining genomic integrity. UV radiation exposure may induce ROS formation, potentially leading to cell death, genomic instability or malignant transformation (14). Therefore, it is important to understand whether and how SPATA12 responds to oxidative damage. The present study will provide a perspective for understanding 
the biological function of the SPATA12 gene in DNA damage induced by oxidative stress.

\section{Materials and methods}

Cell culture, cell treatment and transient transfection. The human cancer HeLa cell line [strain, CCL-2; American Type Culture Collection (ATCC), Manassas, VA, USA] and MCF-7 (strain, HTB22; ATCC) were cultured in RPMI-1640 (Gibco; Thermo Fisher Scientific, Inc., Waltham, MA, USA) supplemented with $10 \%$ bovine calf serum and $100 \mu \mathrm{g} / \mathrm{ml}$ penicillin and streptomycin. All cell lines were maintained in $5 \% \mathrm{CO}_{2}$ and $95 \%$ humidity at $37^{\circ} \mathrm{C}$.

HeLa or MCF-7 cells were treated with $0,30,50$ or $70 \mu \mathrm{M}$ $\mathrm{H}_{2} \mathrm{O}_{2}$ (Sigma-Aldrich; Merck KGaA, Darmstadt, Germany) for $8 \mathrm{~h}$, and then allowed to recover for $4 \mathrm{~h}$. For the resveratrol (Xi'an XiaoCao Botanical Development Co., Ltd., China) treatment, the cells were treated with $20 \mu \mathrm{M}$ dissolved in dimethyl sulfoxide (DMSO) for $12 \mathrm{~h}$. DMSO alone served as a control. For the transfection of empty pRevTRE (Promega Corporation, Madison, WI, USA) or pRevTRE-SPATA12 plasmids synthesized in the laboratory of the College of Biology, Hunan University (Changsha, China), cells were seeded in 6-well plates $24 \mathrm{~h}$ prior to transfection, and then treated with TurboFect ${ }^{\mathrm{TM}}$ in vitro Transfection Reagent (Fermentas; Thermo Fisher Scientific, Inc.) and the plasmids, according to the manufacturer's protocol. Subsequent to transfection, the cells were harvested, washed in PBS (137 mM NaCl, $2.7 \mathrm{mM}$ $\left.\mathrm{KCl}, 8.1 \mathrm{mM} \mathrm{Na}_{2} \mathrm{HPO}_{4}, 1.5 \mathrm{mM} \mathrm{KH} \mathrm{PO}_{4}, \mathrm{pH} 7.4\right)$ and lysed in lysis buffer; cell pellets were used for further analyses.

Cell viability assay. An MTT assay was used to assess the viability of cells following treatment with $0,30,50$ or $70 \mu \mathrm{M} \mathrm{H}_{2} \mathrm{O}_{2}$. HeLa or MCF-7 cells were plated at a density of $1 \times 10^{4}$ cells $/ 100 \mu \mathrm{l}$ in 96 -well plates. Subsequent to $\mathrm{H}_{2} \mathrm{O}_{2}$ treatment, cells were treated with $10 \mu \mathrm{l}$ MTT solution (final concentration, $0.5 \mathrm{mg} / \mathrm{ml}$ ), and the plates were incubated for $4 \mathrm{~h}$ in a humidified incubator at $37^{\circ} \mathrm{C}$ to allow the MTT to be metabolized. The formazan crystals formed in the cells were solubilized with $20 \%$ sodium dodecyl sulfate in $50 \%$ aqueous $\mathrm{N}, \mathrm{N}$-dimethylformamide, and absorbance at $570 \mathrm{~nm}$ was measured with a microplate reader.

Determination of oxidative stress. HeLa or MCF-7 cells were exposed to $0,30,50$ or $70 \mu \mathrm{M} \mathrm{H}_{2} \mathrm{O}_{2}$ for $8 \mathrm{~h}$. Oxidative stress and levels of damage in the cells were assessed according to SOD activity and the GSH and malondialdehyde (MDA) content. All of these were determined, respectively, according to the manufacturer's protocols of an MDA assay kit (cat. no., A003-1), a SOD assay kit (cat. no., A001-1-1) and a reduced GSH assay kit (cat. no., A006-1) (all purchased from Nanjing Jiancheng Bioengineering Institute, Nanjing, China). The total protein concentration of the cells was determined with a BCA Protein Assay kit (Beijing Dingguo Changsheng Biotechnology Co., Ltd., Beijing, China).

RNA isolation. Total RNA was isolated by TRIzol ${ }^{\circledR}$ reagent (Takara Bio, Inc., Otsu, Japan) according to the manufacturer's protocol, digested by RNase-free DNase, and stored at $-80^{\circ} \mathrm{C}$ until use. For quality control, RNA purity and integrity were evaluated by agarose gel electrophoresis and the optical density $(\mathrm{OD})_{260} / \mathrm{OD}_{280}$ ratio, respectively.

Reverse transcription quantitative polymerase chain reaction $(R T-q P C R)$. Single stranded cDNA was synthesized using the first-strand PrimeScript ${ }^{\mathrm{TM}}$ RT Reagent kit with gDNA Eraser (Takara Bio, Inc.) according to the manufacturer's protocol. cDNA was subjected to qPCR using SYBR-Green PCR Master Mix (Tiangen Biotech, Co., Ltd., Beijing, China) and an MX3000 instrument (Stratagene; Agilent Technologies, Inc., Santa Clara, CA, USA). Following initial denaturation for $10 \mathrm{~min}$ at $95^{\circ} \mathrm{C}, 40-45$ cycles of PCR were performed. Each cycle consisted of a denaturing period of $30 \mathrm{sec}$ at $95^{\circ} \mathrm{C}$, and annealing and extension periods for $60 \mathrm{sec}$ at $60^{\circ} \mathrm{C}$. The transcript amount for target genes were normalized to the human glyceraldehyde-3-phosphate dehydrogenase (GAPDH) to control the variability in expression levels and analyzed using the $2-\Delta \Delta \mathrm{Cq}$ method (15). The primer sequences used for qPCR are listed in Table I.

Dual-luciferase reporter assay. All recombinant reporter plasmids of the SPATA12 promoter were constructed by our group in a previous study (16). Firefly and Renilla luciferase-containing plasmids (Promega Corporation) were co-transfected into cells using TurboFect ${ }^{\mathrm{TM}}$ in vitro Transfection Reagent, as previously. A total of $24 \mathrm{~h}$ after transfection, cells were treated as previously and harvested, and firefly and Renilla luciferase activities were determined using a Dual-Luciferase Reporter Assay system (Promega Corporation) on a Modulus ${ }^{\mathrm{TM}}$ luminometer (Turner BioSystems; Thermo Fisher Scientific, Inc.). All reporter assays were performed in triplicate. Non-treated cells were used as the control group.

Hoechst staining. Apoptosis was assessed by a Hoechst 33258 staining kit (Beyotime Institute of Biotechnology, Haimen, China). Following $\mathrm{H}_{2} \mathrm{O}_{2}$ treatment, the cells were stained according to the manufacturer's protocol. Then, the stained cells were observed with a fluorescence microscope (Eclipse TE300; Nikon Corporation, Tokyo, Japan).

Measurement of ROS. Intracellular ROS was measured by the oxidative conversion of the probe 2 ',7'-dichlorofluorescin diacetate (DCFH-DA) into the fluorescent compound DCF using a ROS assay kit (Beyotime Institute of Biotechnology) according to the manufacturer's protocol. In brief, cells treated with or without $\mathrm{H}_{2} \mathrm{O}_{2}$ were collected by centrifugation and washed twice with $50 \mathrm{mM}$ PBS. The cells from each well were then incubated with $10 \mu \mathrm{M}$ DCFH-DA for $20 \mathrm{~min}$ at $37^{\circ} \mathrm{C}$. Following two washes with PBS, the fluorescence of the cells was determined using a fluorescence spectrophotometer (model no. F-2500; Hitachi Ltd., Tokyo, Japan), containing FL solution software at excitation $488 \mathrm{~nm} / \mathrm{emission}$ $529 \mathrm{~nm}$, and fluorescence microscopy. Protein concentrations of the cells were determined with the BCA Protein Assay kit.

Statistical analysis. The results are expressed as the mean \pm standard deviation. Experimental data analyses were performed by one-way analysis of variance with post hoc 
Table I. Primers used for reverse transcription quantitative polymerase chain reaction analysis.

\begin{tabular}{|c|c|c|c|}
\hline Gene & Gene ID & Primer sequence ( $\left.5^{\prime}-3^{\prime}\right)$ & Product length, bp \\
\hline Sirtuin 1 & XM_006717737 & $\begin{array}{l}\text { F: CAGTGAGAAAATGCTGGCCT } \\
\text { R: AAACTTGGACTCTGGCATGT }\end{array}$ & 199 \\
\hline 8-oxoguanine DNA glycosylase & NM_002542 & $\begin{array}{l}\text { F: TACCGAGGAGACAAGAGCC } \\
\text { R: ATGAGCCGAGGTCCAAAA }\end{array}$ & 281 \\
\hline Spermatogenesis-associated gene 12 & NM_181727 & $\begin{array}{l}\text { F: TCACCTTCCCCTCATCTCCC } \\
\text { R: TTTCACGCTTGTCCACTTTC }\end{array}$ & 170 \\
\hline GAPDH & NM_001289746 & $\begin{array}{l}\text { F: GTCTCCTCTGACTTCAACAGCG } \\
\text { R: ACCACCCTGTTGCTGTAGCCAA }\end{array}$ & 131 \\
\hline
\end{tabular}

F, forward primer; $R$, reverse primer.

analysis using a Dunnett's test to determine the significant differences among groups. Statistical analyses were performed using SPSS software, version 17.0 (SPSS Inc., Chicago, IL, USA). $\mathrm{P}<0.05$ was considered to indicate a statistically significant difference.

\section{Results}

Establishment of cellular oxidative damage model by $\mathrm{H}_{2} \mathrm{O}_{2}$. Oxidative stress was first assessed by measuring cell viability, and the data of the MTT assay demonstrated that $\mathrm{H}_{2} \mathrm{O}_{2}$ treatment decreased cell survival in HeLa and $\mathrm{MCF}-7$ cells in a dose-dependent manner (Fig. 1A). HeLa cells appeared to be more vulnerable compared with the MCF-7 cells to $\mathrm{H}_{2} \mathrm{O}_{2}$. Subsequently, SOD activities and GSH and MDA levels were detected in the HeLa and MCF-7 cells. Compared with $0 \mu \mathrm{M}$ $\mathrm{H}_{2} \mathrm{O}_{2}$ control group, the SOD activity and GSH content in HeLa cells with $\mathrm{H}_{2} \mathrm{O}_{2}$ exposure were decreased significantly in a concentration-dependent manner $(\mathrm{P}<0.01)$, whereas the MDA level was markedly increased, reaching a peak at $70 \mu \mathrm{M}(\mathrm{P}<0.01$, Fig. 1B-D), indicating an increase in the levels of oxidative stress experienced by the cells. Similar patterns were observed in MCF-7 cells. These results suggested that the antioxidant defense system is damaged in cells following $\mathrm{H}_{2} \mathrm{O}_{2}$ exposure.

$\mathrm{H}_{2} \mathrm{O}_{2}$ exposure upregulates the expression of SPATA12 mRNA. The expression of SPATA12 mRNA was detected by qPCR in order to determine whether it was active in the cellular response to oxidative stress. As demonstrated in Fig. $2 \mathrm{~A}, \mathrm{H}_{2} \mathrm{O}_{2}$ significantly increased the mRNA expression of SPATA12 in the HeLa $(\mathrm{P}<0.01$ at 50 and $70 \mu \mathrm{M})$ and in the MCF-7 cells $(\mathrm{P}<0.05$ at $50 \mu \mathrm{M}, \mathrm{P}<0.01$ at $70 \mu \mathrm{M})$. As a control, the expression levels of two antioxidant genes, Sirtuin 1 (SIRT1) and 8-oxoguanine DNA glycosylase $1(O G G 1)$, were also examined. SIRT1 and $O G G 1$ are generally used as biomarkers to evaluate the level of oxidative stress in cells (17-19). Consistent with the previous studies, $\mathrm{H}_{2} \mathrm{O}_{2}$ at high concentrations (50 or $70 \mu \mathrm{M})$ markedly increased the level of SIRT1 mRNA ( $\mathrm{P}<0.01$, Fig. 2B), while oxidative stress suppressed the levels of $O G G 1$ mRNA $(\mathrm{P}<0.01$, Fig. 2C) $(17,18)$. These results indicated that SPATA12 may be upregulated by $\mathrm{H}_{2} \mathrm{O}_{2}$ stimulation.
SPATA12 functions as an antioxidant. The levels of the aforementioned oxidative parameters (SOD activity, and GSH and MDA levels) were examined following SPATA12 gene transfection into HeLa or MCF-7 cells to understand its role in oxidative damage. Fig. 3A demonstrates that SPATA12 expression did not alter SOD activity or GSH content following oxidative damage to cells. However, it was observed that SPATA12 expression significantly reduced the induction of MDA by $\mathrm{H}_{2} \mathrm{O}_{2}(\mathrm{P}<0.05$ in HeLa cells, $\mathrm{P}<0.01$ in MCF-7 cells). Subsequently, intracellular ROS production was assessed by measuring the oxidation of DCFH-DA, to investigate the potential protective action of SPATA12 against oxidative stress. DCFH-DA can cross cell membranes and is hydrolyzed enzymatically by intracellular esterases to form non-fluorescent DCFH. Intracellular ROS may oxidize DCFH into the fluorescent DCF; therefore, the intensity of DCF fluorescence is directly proportional to the level of intracellular ROS (20). Compared with the control group, SPATA12 attenuated the levels of $\mathrm{H}_{2} \mathrm{O}_{2}$-induced DCF green fluorescence $(\mathrm{P}<0.01$ vs. control group, $\mathrm{P}<0.05$ vs. pRevTRE group), indicating a reduction in the levels of oxidative stress experienced by the cells (Fig. 3B). Additionally, using a Hoechst staining experiment, a decrease in evident chromatin condensation was observed in the superposition field of view following SPATA12 gene transfection, which demonstrated that apoptosis induced by $\mathrm{H}_{2} \mathrm{O}_{2}$ (70 $\mu \mathrm{M})$ was suppressed by SPATA12 expression (Fig. 3C). These data suggested that the SPATA12 gene functions as an antioxidant through attenuating the level of MDA and ROS, and inhibiting $\mathrm{H}_{2} \mathrm{O}_{2}$-induced apoptosis.

Activator protein-1 (AP-1) may be involved in the transcriptional upregulation of SPATA12 in response to $\mathrm{H}_{2} \mathrm{O}_{2}$. AP-1 is a transcription factor that is sensitive to oxidative stress (21). Our previous study demonstrated that the SPATA12 core promoter is located at 77-302 bp, and the AP-1 transcription factor binding site in this core region (Fig. 4A) is essential to the promoter activity and involved in the transcriptional upregulation of SPATA12 in response to UVC radiation $(13,16)$. In order to investigate the change in SPATA12 promoter activity in response to $\mathrm{H}_{2} \mathrm{O}_{2}$ and the potential role of the AP-1 binding site during this oxidative damage process, the effect of $\mathrm{H}_{2} \mathrm{O}_{2}$ on the activity of a series of SPATA12 gene promoters, including the full-length promoter pGL3-958/302, 

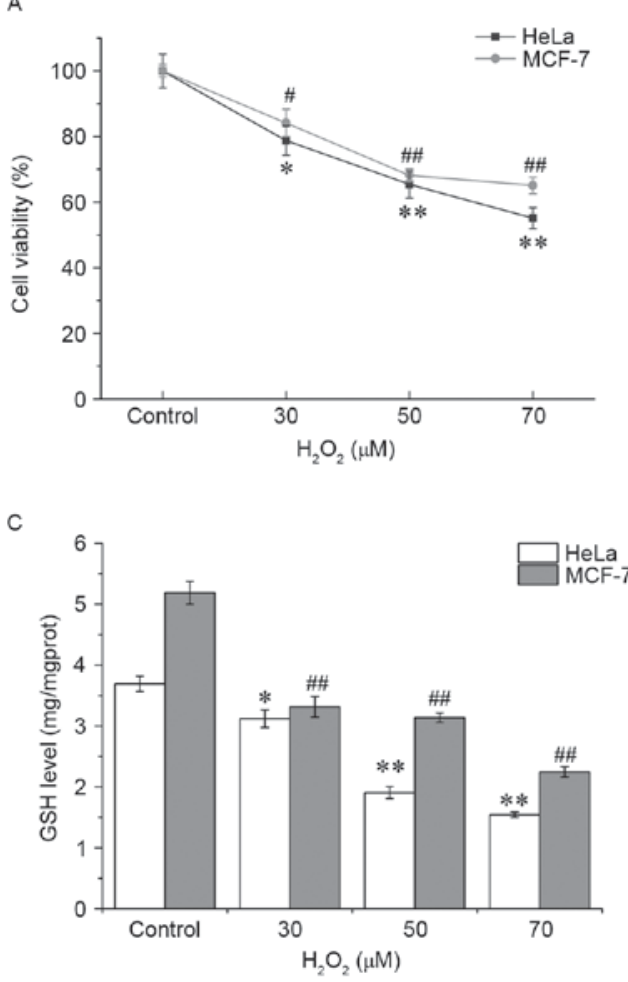

B

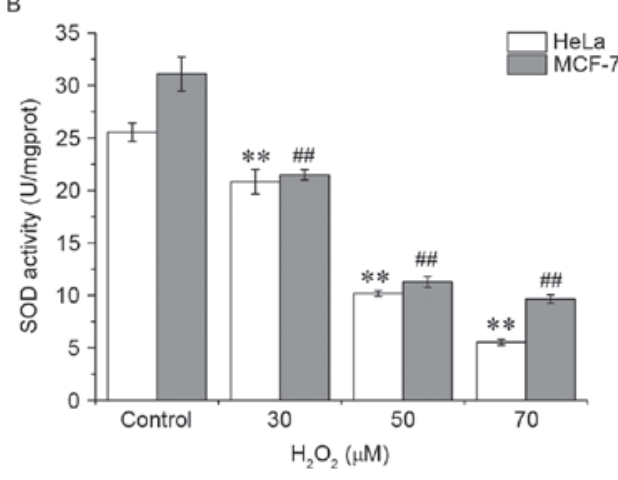

D

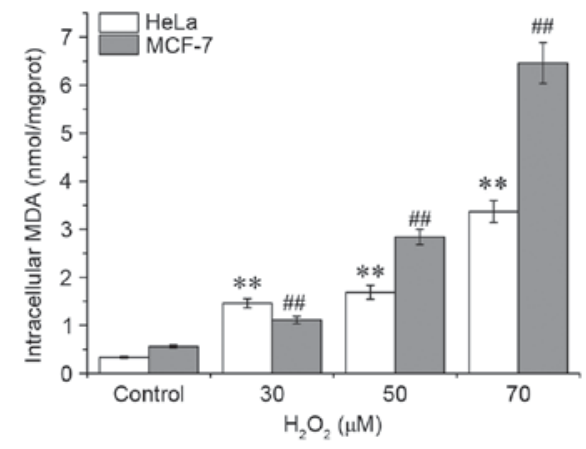

Figure 1. Establishment of the model of the $\mathrm{H}_{2} \mathrm{O}_{2}$ induction of cellular oxidative damage. (A) Effect of $\mathrm{H}_{2} \mathrm{O}_{2}$ on HeLa and MCF-7 cells detected by an MTT assay. The viability of the $0 \mu \mathrm{M} \mathrm{H}_{2} \mathrm{O}_{2}$ control cells was defined as $100 \%$. The effects of $\mathrm{H} 2 \mathrm{O} 2$ on the (B) SOD activity, and the (C) GSH and (D) MDA content in cells were analyzed. The data are presented as the mean \pm standard deviation $(\mathrm{n}=5)$. ${ }^{*} \mathrm{P}<0.05,{ }^{* * *} \mathrm{P}<0.01$ vs. control group for HeLa, and ${ }^{\#} \mathrm{P}<0.05$ and ${ }^{\# \#} \mathrm{P}<0.01$ vs. control group for MCF-7. SOD, superoxide dismutase; GSH, glutathione; MDA, malondialdehyde.

and the truncated promoter fragments pGL3-946/90 and pGL3-136/302 that were constructed in our previous study (16), were analyzed using a dual luciferase reporter gene assay. The pGL3-136/302 and pGL3-958/302 fragments, with the exception of pGL3-946/90, contain the core promoter sequence. Fig. $4 \mathrm{~A}$ indicates that the luciferase activity level of the pGL3-946/90 promoter fragment was unchanged, while the activity levels of pGL3-958/302 and pGL3-136/302 were increased significantly following $\mathrm{H}_{2} \mathrm{O}_{2}$ treatment $(\mathrm{P}<0.01)$, indicating that the SPATA12 gene was upregulated by $\mathrm{H}_{2} \mathrm{O}_{2}$ at the mRNA level. This result was concordant with the data obtained in the qPCR assay.

The AP-1 binding site within the SPATA12 core promoter (77-302 bp) encompasses the sequence 5'-TGAGTCA-3', a core sequence in the AP-1 motif also known as the TPA responsive element (TRE) (22), is demonstrated in Fig. 4B. The point mutation construct pGL3-136/302 (mut 132-134) and the deletion construct pGL3-136/302 (del 132-134) were generated in our previous study (16). As demonstrated by Fig. 4B, the relative luciferase activity of the promoter in the cells with $\mathrm{H}_{2} \mathrm{O}_{2}$ stimulation was reduced when the TRE was mutated or deleted $(\mathrm{P}<0.01)$. This result revealed that TRE within the SPATA12 promoter is of major importance for the responsiveness of this transcription unit to $\mathrm{H}_{2} \mathrm{O}_{2}$ treatment, and that AP-1 may be involved in the $\mathrm{H}_{2} \mathrm{O}_{2}$-induced transcriptional upregulation of SPATA12.

Resveratrol upregulates the expression of SPATA12 via the $A P-1$ binding site. It has been suggested that resveratrol may improve the expression of AP-1 targeted genes by enhancing the activity of AP-1 (23). We hypothesized that resveratrol may increase the expression of SPATA12 by inducing AP-1. With an MTT assay (data not shown), the cytotoxicity of resveratrol at different concentrations was examined, and the nontoxic treatment of $20 \mu \mathrm{M}$ was selected for use on cells for $12 \mathrm{~h}$. As demonstrated in Fig. 5A, resveratrol treatment increased the expression of SPATA12 mRNA in HeLa and MCF-7 cells $(\mathrm{P}<0.01$ in HeLa cells, $\mathrm{P}<0.05$ in $\mathrm{MCF}-7$ cells). Then, a dual luciferase reporter assay was used to detect the effect of resveratrol on the activity of the SPATA12 core promoter with the AP-1 binding site. As indicated in Fig. 5B, the luciferase activity of the pGL3-136/302 promoter (wild-type TRE) was increased following resveratrol treatment $(\mathrm{P}<0.01)$, but decreased markedly when TRE was mutated or deleted $(\mathrm{P}<0.01)$. These results indicated that resveratrol may upregulate the transcription level of SPATA12 via the AP-1 binding site, and it may be used as an activator of SPATA12.

\section{Discussion}

Cellular antioxidant defenses are complex, and act to minimize the levels of ROS while simultaneously allowing ROS to serve their useful functions in cell signaling and redox regulation (24). It has been demonstrated that a number of essential maintenance repair systems become deficient in tumor cells, resulting in the accumulation of cellular damage (25).

Based on our previous studies, we hypothesized that SPATA12 may exhibit antioxidant properties. As $\mathrm{H}_{2} \mathrm{O}_{2}$ is relatively stable and easy to use, it is an important tool for the study of various types of oxidative damage (26). In the present 

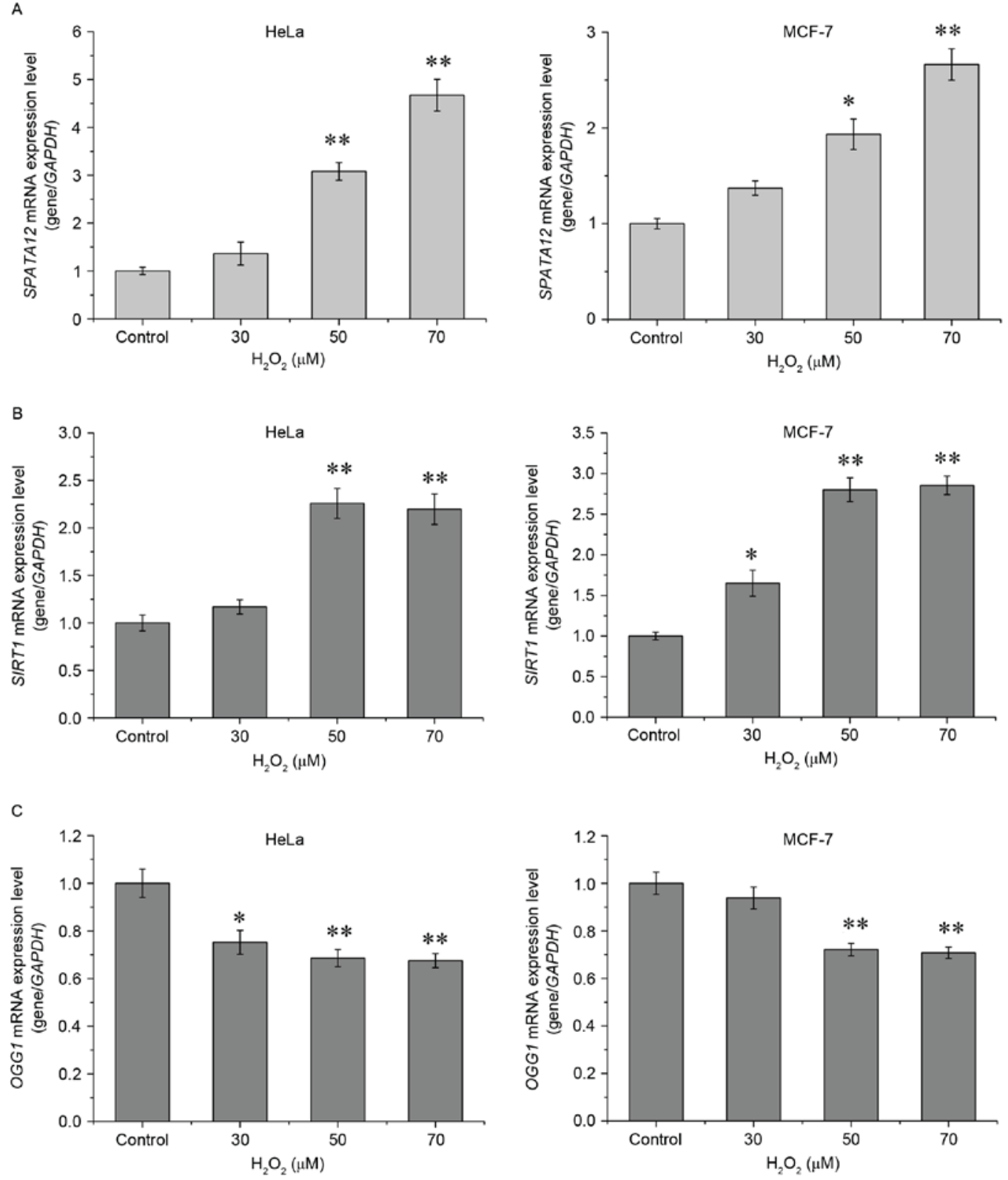

Figure 2. mRNA expression of SPATA12, SIRT1 and OGG1 in HeLa and MCF-7 cells following treatment with $\mathrm{H}_{2} \mathrm{O}_{2}$. The expression of (A) SPATA12, (B) SIRT1 and (C) OGG1 mRNA. The data are presented as the mean \pm standard deviation $(\mathrm{n}=3)$. ${ }^{*} \mathrm{P}<0.05,{ }^{* *} \mathrm{P}<0.01$ vs. the control $\left(0 \mu \mathrm{M} \mathrm{H}_{2} \mathrm{O}_{2}\right)$. SIRT1, Sirtuin 1; OGG1, 8-oxoguanine DNA glycosylase; SPATA12, spermatogenesis-associated gene 12.

study, exogenous $\mathrm{H}_{2} \mathrm{O}_{2}$ was employed to induce oxidative stress and establish a model of cellular oxidative damage. As demonstrated in Fig. 1, compared with the control group, the SOD activity and the GSH level in the HeLa and MCF7 cells exposed to $\mathrm{H}_{2} \mathrm{O}_{2}$ were decreased significantly in a dose-dependent manner, whereas the MDA level was increased, indicating that oxidative stress was generated following $\mathrm{H}_{2} \mathrm{O}_{2}$ treatment. In addition, $\mathrm{H}_{2} \mathrm{O}_{2}$ may increase and decrease the expression levels of SIRT1 and OGGI, respectively, at the mRNA level, which is consistent with previous studies, and demonstrates oxidative damage in these cells $(17,27)$. Using this model for cellular oxidative damage, an increase in SPATA12 expression was identified, suggesting that SPATA12 responded to oxidative stress.

Subsequently, the potential role of SPATA12 in the process of oxidative damage was considered. Fig. 3 demonstrated that the expression of SPATA12 reduced the MDA content, but not the SOD activity or GSH content. Under the same experimental conditions, SPATA12 was observed to reduce the production of ROS caused by $\mathrm{H}_{2} \mathrm{O}_{2}$. In order to further confirm the antioxidant function of the SPATA12 gene, Hoechst staining was performed, and the results indicated that SPATA12 inhibited $\mathrm{H}_{2} \mathrm{O}_{2}$-induced apoptosis. Taken together, these results implied that the SPATA12 gene may have an antioxidant role, and that this function may be achieved by decreasing the ROS and MDA content of cells.

In an attempt to obtain more insight into the underlying mechanism of the SPATA12 gene in oxidative damage, the changes in SPATA12 promoter activity in response to $\mathrm{H}_{2} \mathrm{O}_{2}$ stimulation and the possible roles of the transcription factor binding sites during this process were discussed. Following $\mathrm{H}_{2} \mathrm{O}_{2}$ treatment, the activity of the full-length promoter 

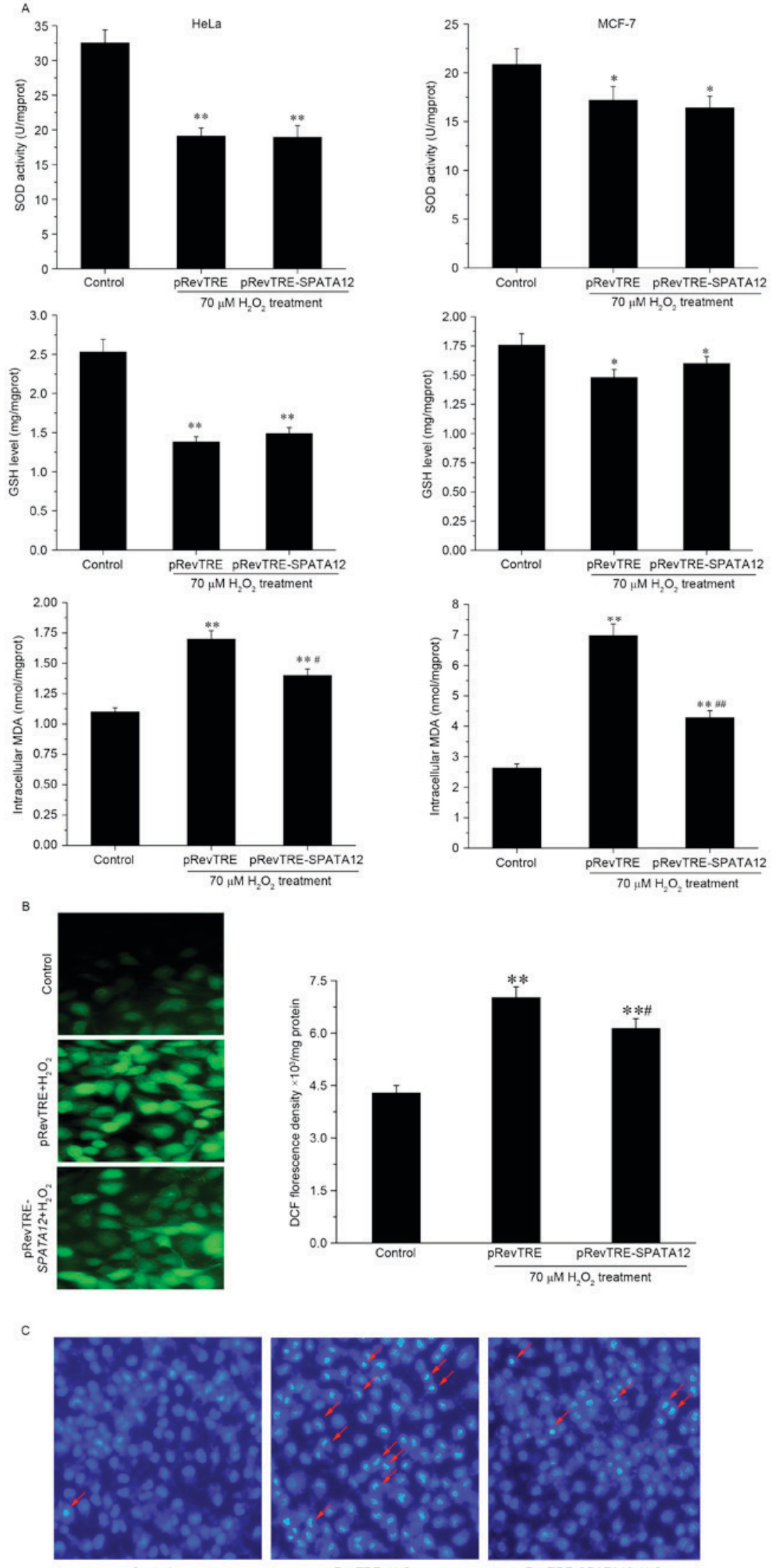

PRevTRE $+\mathrm{H}_{2} \mathrm{O}_{2}$

PREVTRE-SPATA12+ $\mathrm{H}_{2} \mathrm{O}$

Figure 3. Role of SPATA12 expression in oxidative damage. (A) The effect of SPATA12 on intracellular SOD activity, and GSH and MDA content in HeLa and MCF-7 cells following $\mathrm{H}_{2} \mathrm{O}_{2}$ treatment. (B) The effect of SPATA12 on ROS production induced by $\mathrm{H}_{2} \mathrm{O}_{2}$ was observed by fluorescence microscopy (left panel; magnification, $\mathrm{x} 400$ ) and spectrophotometry (right). (C) SPATA12 inhibited the apoptosis induced by $\mathrm{H}_{2} \mathrm{O}_{2}$ in HeLa cells. The apoptosis was detected by Hoechst staining. Crescent-shaped blue fluorescence staining was observed in cells treated by $\mathrm{H}_{2} \mathrm{O}_{2}$; the red arrow indicates the apoptotic cells with visible chromatin condensation (magnification, $\mathrm{x} 100)$. The data are presented as mean \pm standard deviation $(\mathrm{n}=3) .{ }^{*} \mathrm{P}<0.05,{ }^{* *} \mathrm{P}<0.01$ vs. the control group $(0 \mu \mathrm{M}$ $\mathrm{H}_{2} \mathrm{O}_{2}$ and no plasmid transfection), ${ }^{\#} \mathrm{P}<0.05$, ${ }^{\# \prime} \mathrm{P}<0.01$ vs. pRevTRE group. SOD, superoxide dismutase; GSH, glutathione; MDA, malondialdehyde; TRE, TPA-responsive element; SPATA12, spermatogenesis-associated gene 12 . 
A
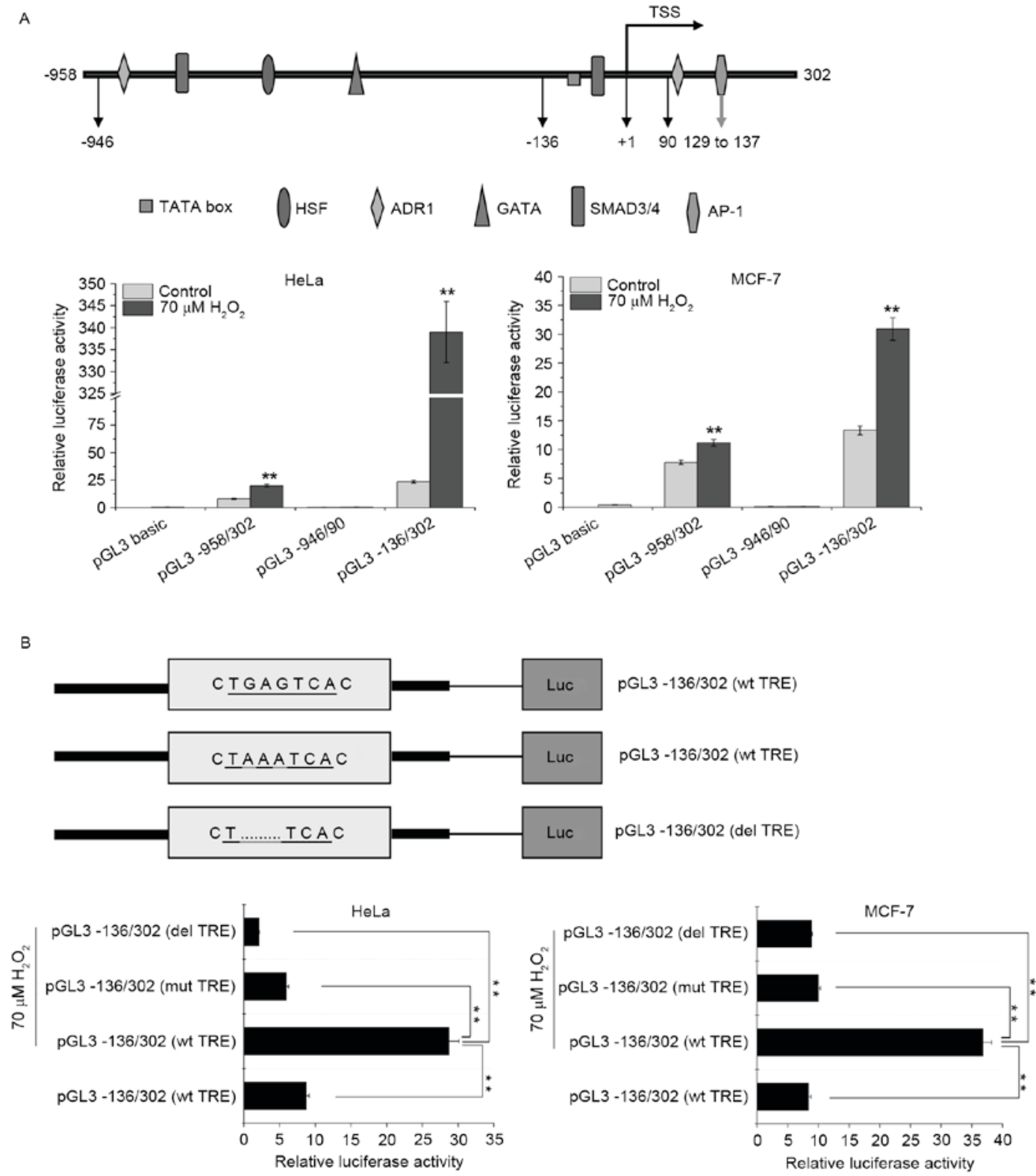

Figure 4. AP-1 may be involved in the transcriptional upregulation of SPATA12 in response to the induction of oxidative stress by $\mathrm{H}_{2} \mathrm{O}_{2}$. (A) Top panel: Schematic representation of the upstream and 5'-untranslated regions of the SPATA12 gene. Bottom panel: Effects of $\mathrm{H}_{2} \mathrm{O}_{2}$ on the activity level of full length and truncated constructs of the SPATA12 promoter in the HeLa and MCF-7 cells. ${ }^{* *} \mathrm{P}<0.01$ vs. $0 \mu \mathrm{M} \mathrm{H}_{2} \mathrm{O}_{2}$ control. (B) Top panel: Schematic illustration of the luciferase reporter constructs within the SPATA12 core promoter pGL3-136/302 (wt, mut, del). The sequence in the rectangular box indicates the AP-1 binding motif, and the section underlined is the TRE element of the AP-1 binding motif. Bottom panel: The relative luciferase activity of the SPATA12 core promoter pGL3-136/302 in cells with or without $\mathrm{H}_{2} \mathrm{O}_{2}$ treatment. All SPATA12 promoter fragments, including the wt, mut and del versions of the TRE element constructs were linked with the firefly luciferase gene in the pGL3-basic vector and the recombinant plasmids were transiently co-transfected with a Renilla plasmid into cells prior to $\mathrm{H}_{2} \mathrm{O}_{2}$ treatment. The pGL3-basic vector was used as a negative control. Renilla luciferase was used as an internal control. ${ }^{* *} \mathrm{P}<0.01$. Data are presented as the mean $\pm \mathrm{SD}(\mathrm{n}=3)$. AP-1, activator protein-1; SPATA12, spermatogenesis-associated gene 12; wt, wild type; mut, point mutation; del, insertion deletion; TRE, TPA-responsive element; SD, standard deviation; TSS, transcription start site; HSF, heat shock factor; ADR1, activated disease resistance 1; SMAD3/4, mothers against decapentaplegic homologs 3/4; Luc, luciferase.

(pGL3-958/302) and the core promoter (pGL3-136/302) were increased, which indicated that SPATA12 expression may be induced by $\mathrm{H}_{2} \mathrm{O}_{2}$ at the mRNA level. This result was consistent with the data from the qPCR assay. Conversely, the activity of pGL3-946/90 was very low with or without $\mathrm{H}_{2} \mathrm{O}_{2}$ treatment.

We hypothesized that there may be a negative regulatory element located at the -946 to $90 \mathrm{bp}$ region that may affect the transcriptional activity of the SPATA12 promoter; this requires further consideration and study in the future. Our previous study also demonstrated that the AP-1 binding site in the SPATA12 core promoter region is essential for the activity of SPATA12 promoter (16). AP-1 is a basic leucine zipper transcription factor, which regulates specific gene expression during the process of cell growth, development, differentiation and apoptosis. Through the leucine zipper, AP-1 identifies the TRE in the target genes' promoter regions. AP-1 is also an important oxidative stress-sensitive transcription factor. During oxidation, the activation of AP-1 is primarily mediated by the phosphorylation pathway, 
A

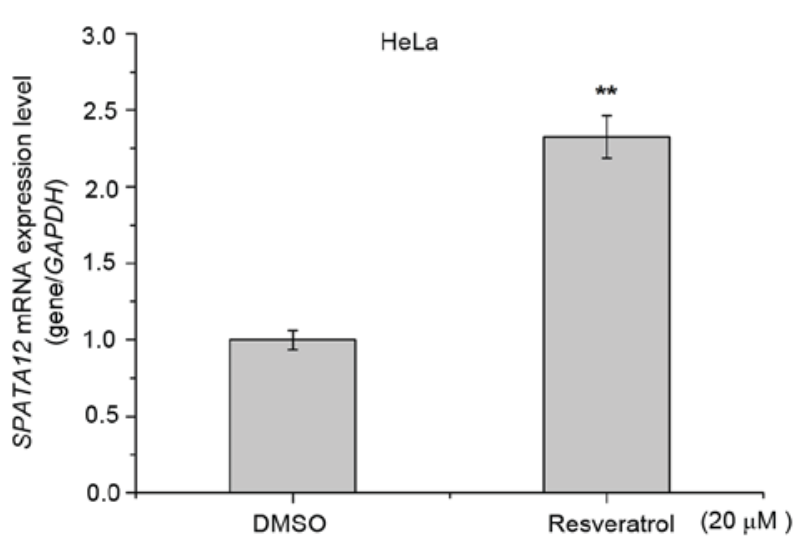

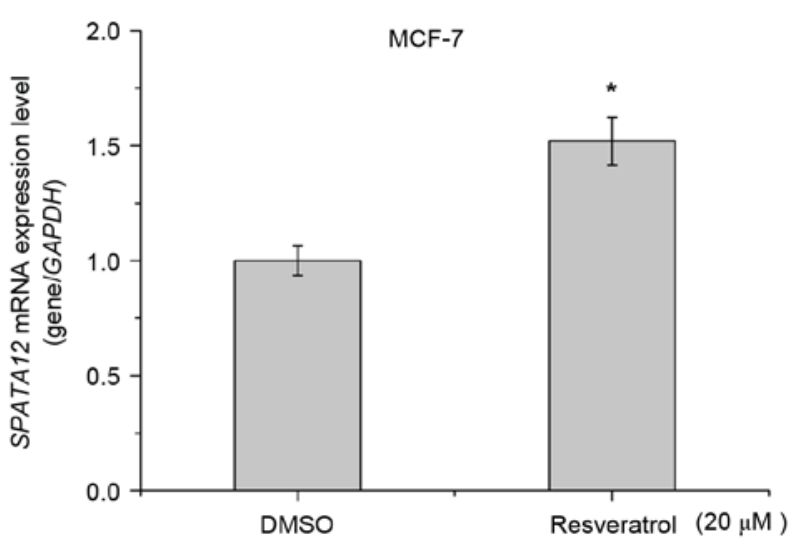

B
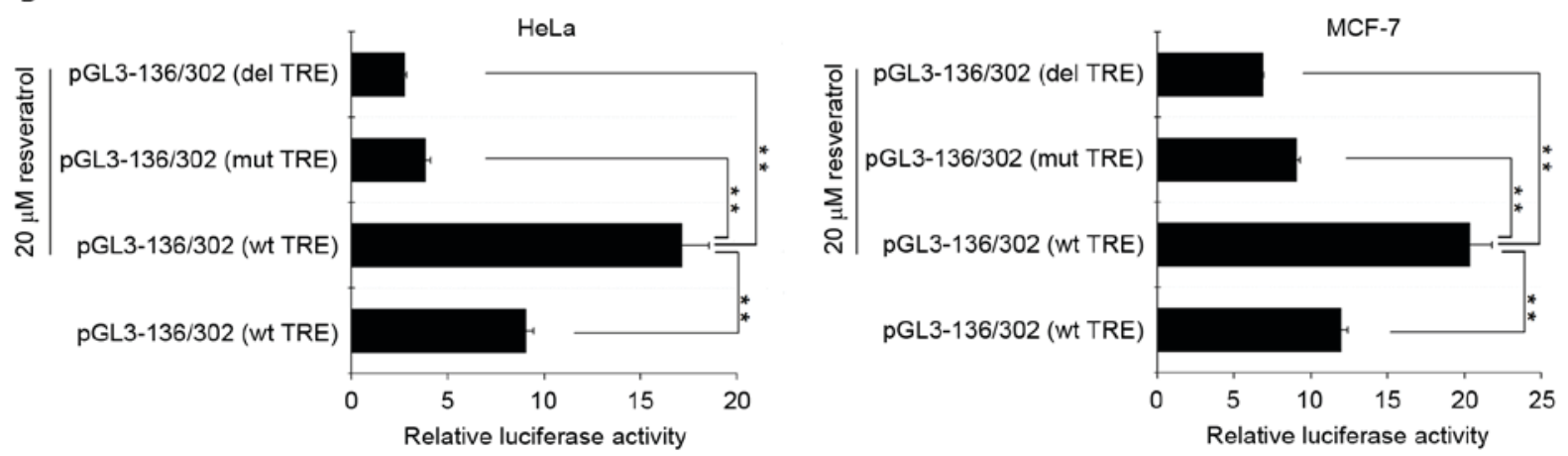

Figure 5. Resveratrol increases the expression of SPATA12 via the AP-1 binding site. (A) Effect of resveratrol on the expression of SPATA12 mRNA in HeLa and MCF-7 cells. The data are presented as the mean $\pm \mathrm{SD}(\mathrm{n}=3)$. ${ }^{*} \mathrm{P}<0.05$ and ${ }^{* *} \mathrm{P}<0.01$ vs. DMSO-only control. (B) Role of AP-1 binding site on the enhancement of SPATA12 promoter activity induced by resveratrol. The data are presented as mean $\pm \mathrm{SD}(\mathrm{n}=3) .{ }^{* *} \mathrm{P}<0.01$. SPATA12, spermatogenesis-associated gene 12; AP-1, activator protein-1; SD, standard deviation; DMSO, dimethyl sulfoxide; wt, wild type; mut, point mutation; del, insertion deletion; TRE, TPA-responsive element.

through c-Jun N-terminal kinase (JNK). Generally, JNK is activated by ROS in cells; the activated JNK consequently activates the c-Jun and c-Fos proteins, inducing the transcriptional activity of AP-1, which promotes the expression of target genes. AP-1 binding sites exist on the c-Jun gene promoter, and the activation of AP-1 may further induce the transcription of c-Jun by combining with this site, forming a positive feedback loop that induces a cascade (28). In the present study, the data from the dual luciferase reporter gene assay indicated that AP-1 mediated the response of SPATA12 to $\mathrm{H}_{2} \mathrm{O}_{2}$ stimulation, and the TRE element of the AP-1 binding site served a key role during this process. This suggests that SPATA12 may respond to oxidative damage via AP-1, and may have the ability to withstand cellular oxidative damage.

Due to the toxicity of synthetic antioxidants, including butylhydroxyanisole and butylhydroxytoluene, previous studies have attempted to identify natural active ingredients with antioxidant functions from plants and herbs for application as clinical chemotherapeutics or daily health care products (29). The efficacy and safety of an increasing number of Chinese herbal monomer components have been confirmed (30). Traditional Chinese Medicine features a variety of antioxidants, including agents that act as stimulating factors to activate the antioxidant cell signaling pathways, regulate the expression of downstream target genes and serve unique roles in the defense against oxidative damage (31). Thiel and Rössler (23), identified that resveratrol may activate the transcriptional expression of AP-1-targeted genes. Therefore, we hypothesized that resveratrol may also regulate the expression of SPATA12. The results of the qPCR assay performed in the present study confirmed this hypothesis, and the dual luciferase reporter gene assay revealed that AP-1 may have mediated the improvement of SPATA12 transcriptional activity by resveratrol.

In conclusion, the data of the present study suggest that the antioxidant properties of SPATA12 are associated with its ability to decrease the levels of ROS and MDA in tumor cells. Under oxidative stress, SPATA12 was able to inhibit oxidative damage and apoptosis induced by $\mathrm{H}_{2} \mathrm{O}_{2}$, to a certain extent. The regulation of AP-1 may be one mechanism to induce the antioxidant activity of SPATA12 during the process of oxidative DNA damage. In addition, resveratrol may activate the expression of SPATA12 via AP-1, which may be considered a potential activator of the SPATA12 gene.

\section{Acknowledgements}

The present study was supported by the National Natural Science Foundation of China (grant no. 81270735). 


\section{References}

1. Han YH, Moon HJ, You BR, Kim SZ, Kim SH and Park WH: The effects of buthionine sulfoximine, diethyldithiocarbamate or 3-amino-1,2,4-triazole on propyl gallate-treated HeLa cells in relation to cell growth, reactive oxygen species and glutathione. Int J Mol Med 24: 261-268, 2009.

2. Ding B, Chi SG, Kim SH, Kang S, Cho JH, Kim DS and Cho NH: Role of p53 in antioxidant defense of HPV-positive cervical carcinoma cells following $\mathrm{H} 2 \mathrm{O} 2$ exposure. J Cell Sci 120: 2284-2294, 2007.

3. Pallepati P and Averill-Bates DA: Activation of ER stress and apoptosis by hydrogen peroxide in HeLa cells: Protective role of mild heat preconditioning at $40^{\circ} \mathrm{C}$. Biochim Biophys Acta 1813: 1987-1999, 2011.

4. Thanan R, Oikawa S, Hiraku Y, Ohnishi S, Ma N, Pinlaor S, Yongvanit P, Kawanishi S and Murata M: Oxidative stress and its significant roles in neurodegenerative diseases and cancer. Int J Mol Sci 16: 193-217, 2014.

5. Waris G and Ahsan H: Reactive oxygen species: Role in the development of cancer and various chronic conditions. J Carcinog 5: 14, 2006.

6. Nishikawa M: Reactive oxygen species in tumor metastasis. Cancer Lett 266: 53-59, 2008.

7. Wu WS: The signaling mechanism of ROS in tumor progression. Cancer Metastasis Rev 25: 695-705, 2006.

8. Ray PD, Huang BW and Tsuji Y: Reactive oxygen species (ROS) homeostasis and redox regulation in cellular signaling. Cell Signal 24: 981-990, 2012.

9. Dan L, Lifang Y and Guangxiu L: Expression and possible functions of a novel gene SPATA12 in human testis. J Androl 28: 502-512, 2007.

10. Lin Y, Liu Z, Liu X, Zhang Y, Rong Z and Li D: Microarray-based analysis of the gene expression profile in GC-1 spg cells transfected with spermatogenesis associated gene 12. Int J Mol Med 31: 459-466, 2013

11. Liu Z, Lin Y, Liu X, Yu W, Zhang Y and Li D: Experimental study of inhibition of tumor cell proliferation by a novel gene SPATA12. Zhong Nan Da Xue Xue Bao Yi Xue Ban 37: 222-227, 2012 (In Chinese).

12. Rajagopalan S: Functional analysis of chromodomain helicase DNA binding protein 2(CHD2) mediated genomic stability. $\mathrm{PhD}$ diss., Uni Tennessee, 2010.

13. Zhang Y, Yang L, Lin Y, Rong Z, Liu X and Li D: SPATA12 and its possible role in DNA damage induced by ultraviolet-C. PLoS One 8: e78201, 2013.

14. Nishigori C, Hattori Y and Toyokuni S: Role of reactive oxygen species in skin carcinogenesis. Antioxid Redox Signal 6: 561-570, 2004.

15. Livak KJ and Schmittgen TD: Analysis of relative gene expression data using real-time quantitative PCR and the 2(-Delta Delta C(T)) method. Methods 25: 402-408, 2001.

16. Li D, Lin Y, Liu Z, Zhang Y, Rong Z and Liu X: Transcriptional regulation of human novel gene SPATA12 promoter by AP-1 and HSF. Gene 511: 18-25, 2012.

17. Hasegawa K, Wakino S, Yoshioka K, Tatematsu S, Hara Y, Minakuchi H, Washida N, Tokuyama H, Hayashi K and Itoh H: Sirt1 protects against oxidative stress-induced renal tubular cell apoptosis by the bidirectional regulation of catalase expression. Biochem Biophys Res Commun 372: 51-56, 2008.
18. Yang L, Wang Y, Lin Z, Zhou X, Chen T, He H, Huang H, Yang T, Jiang Y, Xu W, et al: Mitochondrial OGG1 protects against PM2.5-induced oxidative DNA damage in BEAS-2B cells. Exp Mol Pathol 99: 365-373, 2015.

19. Zheng T and Lu Y: SIRT1 protects human lens epithelial cells against oxidative stress by inhibiting p53-dependent apoptosis. Curr Eye Res 41: 1068-1075, 2016.

20. Marimoutou M, Le Sage F, Smadja J, Lefebvre d'Hellencourt C, Gonthier MP and Robert-Da Silva C: Antioxidant polyphenol-rich extracts from the medicinal plants Antirhea borbonica, Doratoxylon apetalum and Gouania mauritiana protect 3T3-L1 preadipocytes against $\mathrm{H} 2 \mathrm{O} 2$, TNF $\alpha$ and LPS inflammatory mediators by regulating the expression of superoxide dismutase and NF- $\kappa$ B genes. J Inflamm (Lond) 12: 10, 2015.

21. Ma Q: Transcriptional responses to oxidative stress: Pathological and toxicological implications. Pharmacol Ther 125: 376-393, 2010.

22. Wang M, Zhu K, Zhang L, Li L and Zhao J: Thioredoxin 1 protects astrocytes from oxidative stress by maintaining peroxiredoxin activity. Mol Med Rep 13: 2864-2870, 2016.

23. Thiel G and Rössler OG: Resveratrol stimulates AP-1-regulated gene transcription. Mol Nutr Food Res 58: 1402-1413, 2014.

24. Halliwell B: Reactive species and antioxidants. Redox biology is a fundamental theme of aerobic life. Plant Physiol 141: 312-322, 2006.

25. Poljsak B, Šuput D and Milisav I: Achieving the balance between ROS and antioxidants: When to use the synthetic antioxidants. Oxid Med Cell Longev 2013: 956792, 2013.

26. Hu TJ, Shuai XH, Chen JR, Wei YY and Zheng RL: Protective effect of a Potentilla anserine polysaccharide on oxidative damages in mice. Int J Biol Macromol 45: 279-283, 2009.

27. Kim KC, Lee IK, Kang KA, Kim HS, Kang SS and Hyun JW: Baicalein (5,6,7-trihydroxyflavone) reduces oxidative stress-induced DNA damage by upregulating the DNA repair system. Cell Biol Toxicol 28: 421-433, 2012.

28. Liebermann DA, Gregory B and Hoffman B: AP-1 (Fos/Jun) transcription factors in hematopoietic differentiation and apoptosis. Int J Oncol 12: 685-700, 1998.

29. Kahl R and Kappus H: Toxicology of the synthetic antioxidants BHA and BHT in comparison with the natural antioxidant vitamin E. Z Lebensm Unters Forsch 196: 329-338, 1993 (In German).

30. Matkowski A,Jamiołkowska-KozlowskaW and Nawrot I: Chinese medicinal herbs as source of antioxidant compounds-where tradition meets the future. Curr Med Chem 20: 984-1004, 2013.

31. Xiong L, Xie J, Song C, Liu J, Zheng J, Liu C, Zhang X, Li P and Wang F: The activation of Nrf2 and its downstream regulated genes mediates the antioxidative activities of xueshuan xinmaining tablet in human umbilical vein endothelial cells. Evid Based Complement Alternat Med 2015: 187265, 2015.

This work is licensed under a Creative Commons Attribution-NonCommercial-NoDerivatives 4.0 International (CC BY-NC-ND 4.0) License. 